\title{
AN EVALUATION OF POSTPARTUM DEPRESSION - A STUDY IN ALBANIA FOR 2015-2017 PERIOD
}

\author{
Mirela Çela ${ }^{1 *}, 3^{*}$, Vuksan Kola ${ }^{2}$ \\ $I^{*}$ Faculty of Medicine, Neuroscience Department - Psychiatric Service, Tirana, Albania; \\ ${ }^{2}$ UHC Mother Teresa, Neuroscience Department, Tirana, Albania; \\ ${ }^{3 *}$ National Center for Quality Safety and Accreditation of Health Institutions, Tirana, Albania; \\ *Corresponding Author Mirela Çela, email: celamirela@gmail.com;
}

Received December 2018; Accepted January 2019; Published February 2019;

DOI: https://doi.org/10.31407/ijees9121

UOI license: http://u-o-i.org/1.01/ijees/04632272

\begin{abstract}
Postpartum depression (PPD) is the most common medical complication of childbearing. Universal screening PPD maximizes the likelihood of prompt identification of it. Based on evidence PPD occurs in 10 to $15 \%$ of new mothers. Groups of women at higher risk include (50-60\%) inner city women, mothers of pre-term infants and adolescents. Depression after delivery persists for more than 7 months in 25-50\% of women. Post-birth depressive episodes may result in maternal social or relational problems even after recovery. In this paper, we are presented the relation of PPD with factors like age, demography, marital status and education level. The methodology we used is Edinburgh Postnatal Depression Scale (EPDS). This self-report instrument contains ten items ranked from 0 to 3 that reflect the patient's experience over the past week. The EPDS has been validated extensively for use in the postpartum period and during pregnancy. In this study are involved to be evaluated for PPD, patients from 4 primary health care centers in Tirana and from two departments of Obstetrical Gynecology University Hospital "Geraldine Queen" in Tirana and to find out the Frequency of depression by time after birth at the target group of this study. Patients that participated in the survey are anonymous in accordance to respect patient's right.
\end{abstract}

Keywords: postpartum depression, frequency. 